\title{
Estimating the Emission Reduction Potential of Australian Transport
}

\author{
David Cosgrove ${ }^{a}$ \\ David Gargett ${ }^{\mathrm{a}}$ \\ Caroline Evans ${ }^{\mathrm{b}}$ \\ Paul Graham ${ }^{\mathrm{c}}$
}

\begin{abstract}
The Australian Low Carbon Transport Forum (ALCTF) - initiated by ARRB Group, BITRE and CSIRO - was organised to gather knowledge on possible options for transport emission abatement, with the participation of a diverse range of government, industry, academic and other research organisations. The ALCTF aimed: to generate a list of options with the potential to significantly improve the efficiency of the Australian transport sector; identify the possible magnitude of greenhouse gas emission reductions for each option, both individually and when combined; examine challenges to achieving the options' full potential and investigate any uncertainties, especially concerning their likely effectiveness. This interdisciplinary study analysed a wide range of emission abatement prospects, covering vehicle and fuel technologies, infrastructure improvements and land-use planning, travel demand management, mode shifts and other behavioural change. A novel aggregation process was developed, to estimate the maximal potential reduction, by 2050 , from a full package of measures acting together - with the results demonstrating that large reductions in currently projected greenhouse gas emission levels should be technically feasible, even with increasing population, without sacrificing access to transport services.
\end{abstract}

\section{Key words: Emission projections; Technology assessment; Infrastructure improvement; Transport demand management}

\section{Introduction}

The Australian Low Carbon Transport Forum (ALCTF) was organised (by a project secretariat comprising ARRB Group, BITRE and CSIRO) in an effort to bring together knowledge on greenhouse gas abatement options for Australian transport, and explore just how deeply future emissions could plausibly be cut across the sector. With the participation of around thirty organisations (ranging across government, industry, academic and other research agencies), a set of emission abatement prospects were evaluated, covering the areas of vehicle and fuel technology, infrastructure improvements, travel demand management, modal shifts and various other behavioural or urban design changes. This paper, which outlines the ALCTF process, and the methodologies used to analyse the feasibility of the

\footnotetext{
${ }^{\text {a }}$ Bureau of Infrastructure, Transport and Regional Economics (BITRE), Canberra ACT 2601

${ }^{\mathrm{b}}$ ARRB Group, Vermont South VIC 3133

${ }^{\mathrm{c}}$ Commonwealth Scientific and Industrial Research Organisation (CSIRO), Newcastle, NSW 2300 http://dx.doi.org/10.14453/isngi2013.proc.56
} 
different options, essentially summarises parts of a detailed report on the project's main results, Greenhouse gas abatement potential of the Australian transport sector: Technical Report ${ }^{1}$.

Basically, the aims of the ALCTF were to generate a comprehensive list of possible options for reducing greenhouse gas emissions from the Australian transport sector; and to identify how significant potential emission reductions could be both for each option acting individually and when combined as an aggregate set of measures. The ALCTF process also strove to examine any obstacles or challenges to achieving the options' full potential, and to investigate any uncertainties or knowledge gaps, especially concerning the options' likely effectiveness, timing or practicality.

\section{Workshop Overview}

The core of the ALCTF process consisted of a series of workshops, with a diverse range of forum participants contributing a wide variety of expert knowledge on possible abatement opportunities. Between July and November 2011, three workshops (one each in Melbourne, Sydney and Brisbane) were conducted. An extensive list of possible abatement options resulted from the workshop discussions, which were then prioritised by the ALCTF participants, selecting a set of measures for analysis (shown in Figure 1) that attempts to cover a reasonable sample of the abatement opportunities likely to be available within the transport sector over the coming decades. The list of options given in Figure 1 is not intended to be exhaustive or prescriptive (that is, it does not claim to contain every single emission abatement measure worthy of consideration), but aims to be roughly representative of the maximal abatement that could potentially be achieved by about 2050 (while roughly maintaining current levels of transport amenity or utility) from an integrated package of transport sector options acting together. Note that 'maximal' here means the amount of emission reductions (relative to currently expected trends) judged (through discussions of the participating organisations) to be approaching the limits of social and economic constraints but remaining technically feasible.

Implementing such a full package of options would entail a range of behavioural and technological changes, both for the transport sector and across the wider Australian community. For example, this may involve policies encouraging: urban road pricing or other congestion management technologies, the control of grossly polluting vehicles, enhanced vehicle fuel efficiency or the accelerated uptake of some technology prospects (such as electric vehicles or second-generation biofuels, for which eventual fleet penetration will partially depend on the resulting future trends in fuel, vehicle and infrastructure prices ); and even some longer-term lifestyle changes (such as could result from workplaces allowing greater use of telecommuting or the greater adoption of walking or cycling following urban re-design).

The latter part of the Workshop process concentrated on investigating how the selected greenhouse gas abatement options might interact when combined, and thus the ALCTF analyses examine the options both individually (as stand-alone alternatives) and as part of an aggregate package of measures (under an 'Aggregate Scenario' aimed at modelling the maximum abatement technically feasible by 2050 from the chosen options all acting together, allowing as much as possible for their likely overlaps or interactions). Workshop participants were also asked to consider likely co-benefits and disbenefits for each option, and to provide 
their views on how much of a challenge possible social or economic constraints might pose to the successful adoption of the various abatement options.

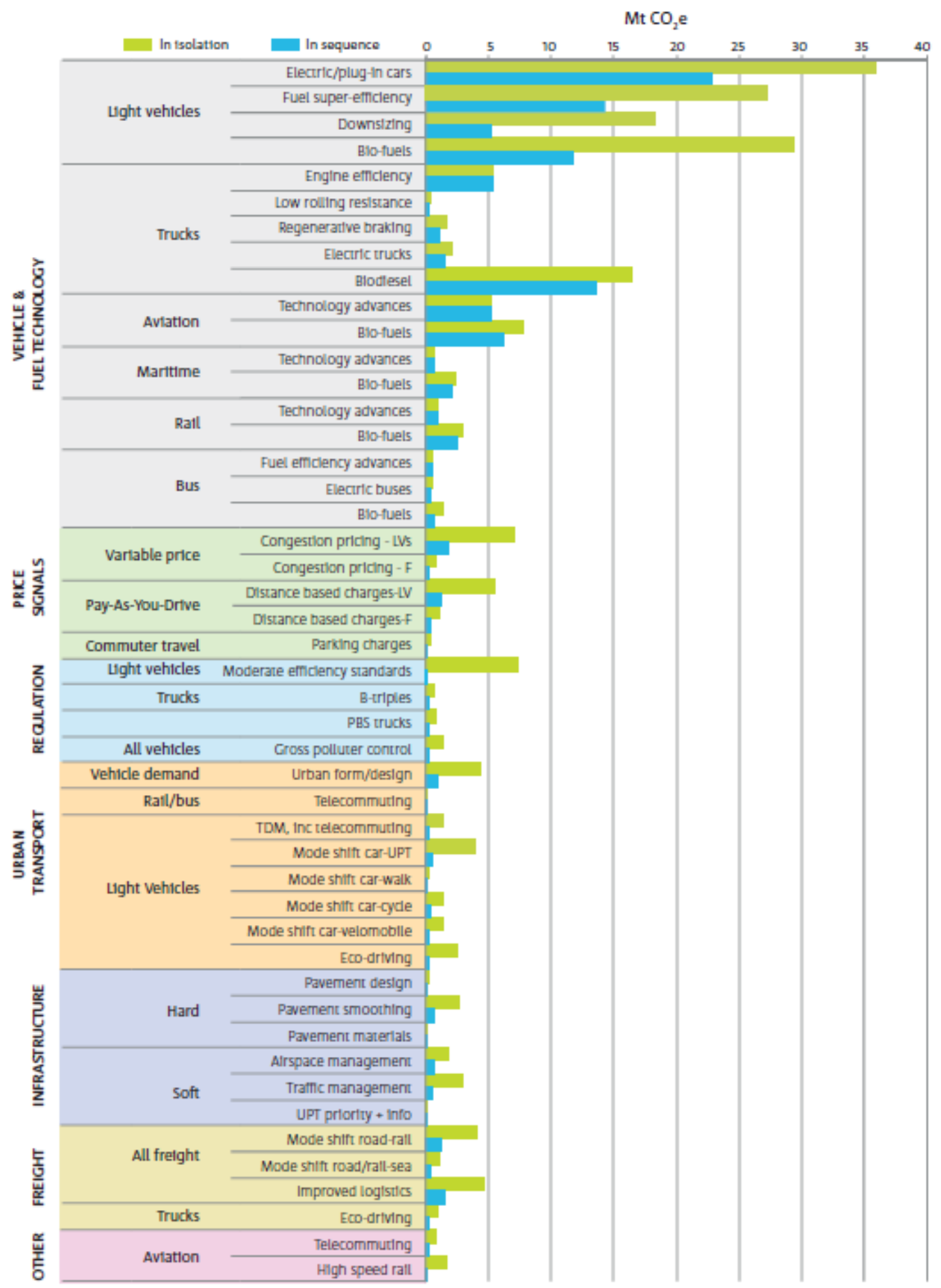

Figure 1. Estimated maximum per annum greenhouse gas reduction that could be achieved by selected transport abatement options, considered in isolation and as an in sequence contribution to a transport sector aggregate, by 2050.

Notes: $\mathbf{L V}$ - light vehicle, $\mathrm{F}$ - freight vehicle.

'In sequence' values strongly depend on the evaluation order chosen for the option aggregation, and are not necessarily representative of actual individual effects or technical potentials.

Sources: Cosgrove et $\mathrm{al}^{1}, \mathrm{CSIRO}^{2}$. 


\section{Abatement Estimation}

Essentially, the amount of abatement an option might achieve is dependent on 1) its level of eventual adoption in a given segment of the transport sector, 2) the greenhouse gas emissions expected in that market segment and 3) how effective the measure is in reducing emissions relative to conventional operating conditions. The ALCTF assessed each of these basic elements, across the set of chosen options.

A calculation of expected abatement has to be made relative to some projection of likely future conditions, usually referred to as a reference or base case. Since the abatement estimates are here calculated in relation to projections of 2050 transport emissions (under a 'base case scenario'), rather than current levels, the particular specification of that reference scenario has a significant bearing on the resulting calculations. For example, any technological prospect assumed to achieve substantial future market share even under business-as-usual trends may have only a slight 2050 abatement potential estimated for any extra market penetration (relative to the reference case) even if offering large efficiency gains relative to current practices. The reference scenario adopted for the ALCTF assessments used base case transport projections developed by BITRE ${ }^{3}$; based on current trends in major economic indicators and demography, with continuing growth in national population (reaching about 36 million persons by 2050) and average income levels (see Treasury ${ }^{4-5}$ ), but only gradually increasing oil prices (using IEA $^{6}$ ).

Road vehicle use per person is expected to exhibit a slight upward trend to 2020, as residual damping effects after the Global Financial Crisis gradually wear off. However past 2020, road vehicle kilometres per person will tend to saturate if currently identified structural trends ${ }^{7}$ continue to hold; and daily travel levels in Australia are likely to increase more slowly in the future than for the long-term historical trend. However, the business-as-usual projections have continuing strong growth in domestic air travel and freight movement (both averaging growth of over 2 per cent per annum over the forecast period 2010-2050). Under the reference scenario assumptions, expected innovation in vehicle and engine technology, leading to gradual improvements in average fuel efficiency, serve to roughly stabilise aggregate end-use energy consumption by Australian domestic transport from about 2040 on (see Figure 2).

Since many of the options being assessed by the ALCTF involve possible changes to fuel supply, solely end-use emission values are not fully suitable for such analyses. For a more complete picture of total emissions output due to Australian transport (especially since enduse values do not include any of the emissions due to electricity use), estimates of full fuel cycle (FFC) emissions are derived for these evaluations. 'Full fuel cycle' values refer to the inclusion of emissions released during transport fuel supply and processing (including from petroleum refining or biofuel production), and during power generation (for electric vehicles or railways), as well as from direct fuel combustion. This means that when any alternative fuels are considered, all emissions associated with their supply are taken into account, which is important since some fuels have considerable upstream emissions, but very low or zero emissions during their use. For example, carbon dioxide emissions from the use of biofuels are traditionally assigned a zero level for emission inventory accounting purposes, assuming that the amount of carbon dioxide from their direct combustion will be reabsorbed when the biofuel feedstock is regrown. However, with FFC evaluations, emissions associated with cultivating, harvesting, transporting, processing and converting the feedstock biomass into 
biofuel are also accounted for, providing the estimates of net emissions from biofuel consumption used in this study.

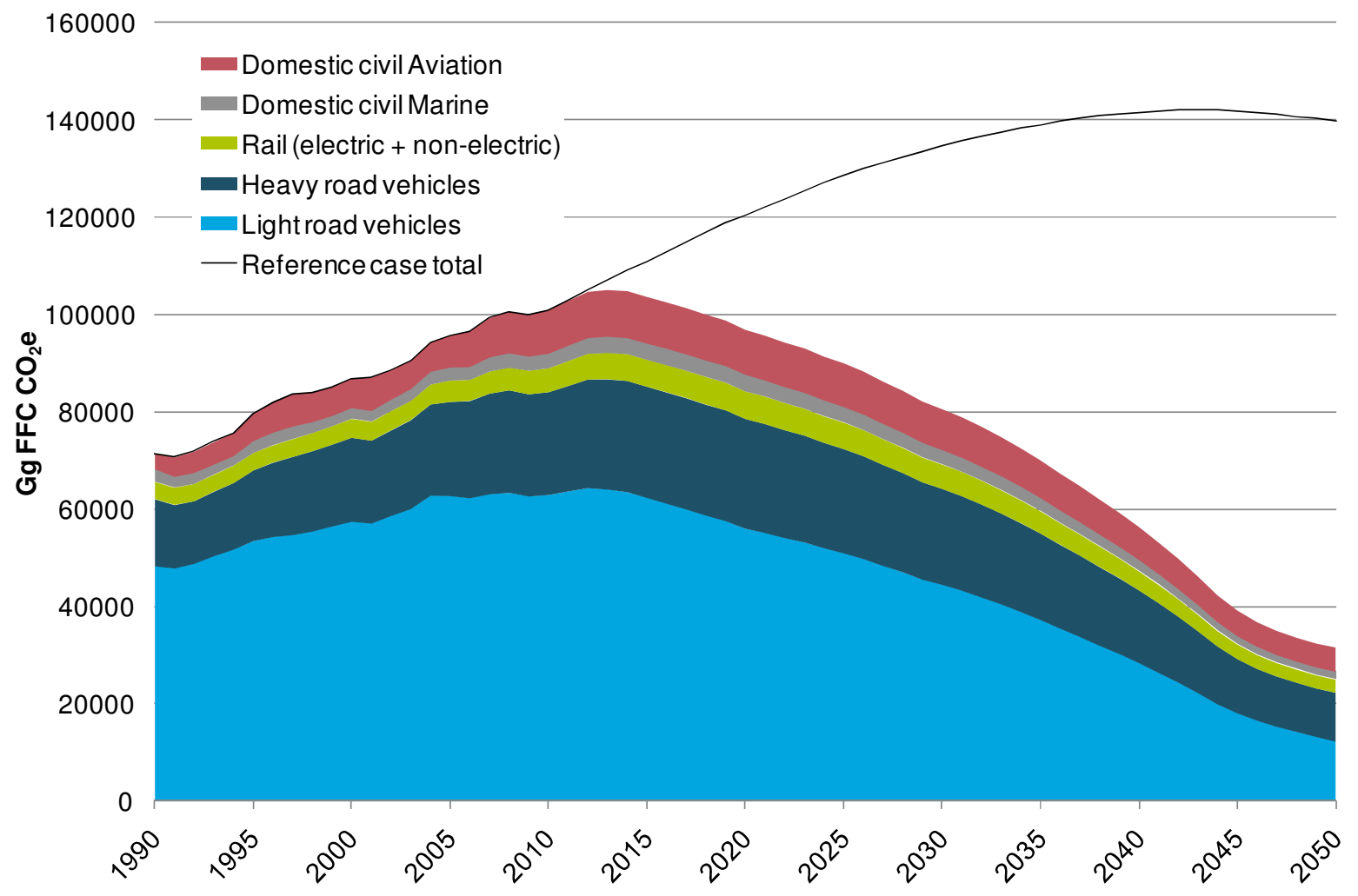

Figure 2. Maximum potential abatement projected for Australian transport sector, ALCTF Aggregate Scenario compared to Base Case projections.

Notes: $\mathrm{CO}_{2}$ equivalent emission values here include only contributions of direct greenhouse gases $\left(\mathrm{CO}_{2}, \mathrm{CH}_{4}\right.$ and $\left.\mathrm{N}_{2} \mathrm{O}\right)$. Full fuel cycle (FFC) estimates include emissions due to energy supply and conversion, as well as from fuel combustion. Net emissions for biofuels are also estimated here. 'Aviation' is all civil domestic aviation (i.e. including general aviation, but excluding military aircraft). 'Marine' consists of emissions from coastal shipping (including any fuel consumed by international vessels undertaking a domestic freight task), ferries and small pleasure craft (and excludes fuel use by military and fishing vessels). 'Light Road Vehicles' include all passenger cars and Sports Utility Vans, Light Commercial Vehicles and motorcycles. 'Heavy road vehicles' include all trucks (rigid and articulated) and buses.

Sources: BITRE estimates, BITRE $^{3}$, Cosgrove et al $^{1}$.

The upstream emission intensities of various fuels are unlikely to remain constant, with some expected to improve considerably over time. For example, it is assumed in these assessments that Australian electricity generation becomes increasingly less carbon intensive, and that biofuels become progressively sourced more from non-food feedstocks typically requiring less resources to produce (such as fertiliser, conversion energy or necessary land area). Specifically, the FFC values derived for the ALCTF assume that the provision of electricity decarbonises over time consistent with Treasury modelling. In the Treasury 'core policy scenario ${ }^{8}$, generation emission intensity (in tonnes of $\mathrm{CO}_{2}$ per megawatt-hour of electricity delivered) is forecast to reduce by about 30 per cent over the next 20 years, and by around 75 per cent by 2050 . Such a reduction in emission intensity significantly improves the appeal of electric vehicles as a transport abatement option. 
In accordance with current National Greenhouse Gas Inventory specifications for reporting of carbon dioxide equivalent $\left(\mathrm{CO}_{2} \mathrm{e}\right)$ quantities $^{9}$ (DCCEE 2010), the values herein include only the effects of the directly radiative gases emitted from transport fuel combustion, comprising carbon dioxide $\left(\mathrm{CO}_{2}\right)$, methane $\left(\mathrm{CH}_{4}\right)$ and nitrous oxide $\left(\mathrm{N}_{2} \mathrm{O}\right)$. Aggregate emission volumes for the reference case in 2050, at approximately 140 thousand gigagrams of direct $\mathrm{CO}_{2} \mathrm{e}$ (where $\mathrm{Gg}=10^{9}$ grams, equivalent to thousand tonnes), are approximately 38 per cent higher than 2010 levels for domestic transport (see upper line in Figure 2).

The green bars in Figure 1 give the results derived for the individual impact of each option 'in isolation' (that is, the emission reduction for that option if all else stayed the same as the reference case) - presented separately for each of the 47 abatement possibilities selected for ALCTF assessment - demonstrating the significant potential of enhancements to vehicle and fuel technologies. Though this allows us to see each option's discrete potential, adding up these 'in isolation' values does not give an appropriate cumulative total, for the possible action of the whole set of options (since such a tally does not adequately account for their overlapping effects). The estimation method for the Aggregate Scenario thus entailed setting an order, for calculating the successive steps of each option's contribution to a summed total; with the sequencing, also given in Figure 1 (options summed from the top of the chart down), being agreed amongst workshop participants as a reasonable evaluation order. The particular order chosen has no objective meaning, and changing this sequence would not alter the final estimate for aggregate abatement, just the individual steps during its computation. That is, if an option were to be moved down the evaluation list, its resulting 'in sequence' abatement value would tend to reduce (since the residual market - or remaining emissions - upon which it now acts, resulting from the actions of all the options higher in the Figure 1 listing, would be correspondingly reduced). Likewise, any options moved up the list would tend to have their 'in sequence' values increase accordingly.

Summing across the 'in sequence' contributions (given by the blue bars in Figure 1) to the ALCTF Aggregate Scenario yields a total sectoral abatement estimate of about 108 thousand gigagrams of direct $\mathrm{CO}_{2} \mathrm{e}$ per annum by 2050 (relative to the business-as-usual assumptions). This corresponds to the abatement potential of all the options acting together being equivalent to a roughly 77 per cent reduction in the (reference scenario) projected level of transport sector emissions (Figure 2). The divergence between the Base Case trend for total FFC greenhouse gas emissions, from Australian civil domestic transport, and levels that could potentially hold - following implementation of a full package of options such as that comprising the ALCTF Aggregate Scenario - widens over time (as displayed in Figure 2, which also shows the estimated modal composition resulting from the set of options' collective activity). That is, under such combined and concerted action, transport emissions are projected to fall to around 32 thousand gigagrams $\mathrm{CO}_{2} \mathrm{e}$ per annum by 2050 .

This particular abatement assessment assumes that a large proportion of Australian vehicles would be capable of running on biofuels/biofuel blends by 2050 , with such fuel use assumed due to bio-derived ethanol and biodiesel from a range of currently available sources $\left(1^{\text {st }}\right.$ generation biofuels) and projected future feedstock materials $\left(2^{\text {nd }}\right.$ generation biofuels). Note that the various biofuel options have some of the greater uncertainty levels associated with their abatement evaluations, since there is considerable on-going debate concerning issues such as: possible land use conflicts with food production; exactly how much biofuel 
volume can be produced sustainably; and how efficient various prototype biofuel production technologies will actually be when operating at large scale ${ }^{\mathrm{d}}$

\section{Conclusions}

Based on extensive input from transport experts, a representative set of 47 individual abatement options for the transport sector were examined in detail, and had their maximal potential for future emission reductions assessed. These included a large number of fuel and vehicle technologies (especially concerning vehicle electrification and biofuel use), urban transport measures, new and alternative infrastructure, and options to modify behaviour via regulation and price signals. The large number of available options identified by the forum testifies to how complex and diverse the transport sector is. The ALCTF process has demonstrated that it should be technically feasible for Australian domestic transport to have its aggregate sectoral emissions decline over time, under the action of an integrated package of measures, to be around 64 per cent lower than year 2000 levels by 2050 (Figure 2), without severely compromising overall transport utility. This reduction could be obtained using a range of technologies either currently available or likely to be commercialised in the near to medium term (assuming certain research or infrastructure developments progress sufficiently over the coming decades, such as decarbonisation of the electricity grid or the adequate availability of affordable $2^{\text {nd }}$ generation biofuels derived from environmentally sustainable feedstocks), and a variety of standard transport demand management options (such as congestion pricing, improvements to freight logistics or mode changes).

The ALCTF scenarios were assessed primarily independent of explicit cost considerations. However, even though the study did not seek precise quantification of the costs of individual options, it appears that incremental investment in the order of \$A5-10 billion per annum (whether public or private, with the major cost components, across the set of options identified here, probably relating to the provision of extra vehicle technology) could be required to implement such a package of abatement measures. Over time, this investment will generally deliver financial benefits, primarily in the form of fuel savings, which are expected to eventually more than offset the incremental costs (that is, deliver net social benefits over the longer term, with the up-front costs more than balanced by advantages such as reduced fuel consumption, traffic congestion improvements or health benefits from better urban air quality).

The aggregation process conducted here is quite approximate in nature, and there are significant uncertainties surrounding many of the abatement assessments, yet such a collective set of options should certainly offer substantial emission reduction potential, as long as any social or economic obstacles to their implementation can be successfully overcome. For example, ongoing global research, development and industrial deployment are

\footnotetext{
${ }^{\mathrm{d}}$ That is, the estimated level of possible abatement is predicated on there being an adequate supply of affordable second-generation biofuels in the future. This will be subject to technological development outcomes and to competing needs for biomass possibly limiting transport sector availability. Based on CSIRO assessments of likely future availability of domestic biofuels (such as Farine et $\mathrm{al}^{10}$ ), the ALCTF scenarios place limits on total biofuel use, where it is assumed that annual abatement greater than about 15-20 million tonnes (Mt) $\mathrm{CO}_{2} \mathrm{e}$ per annum for biodiesel and about 30-35 $\mathrm{Mt} \mathrm{CO}_{2} \mathrm{e}$ per annum for ethanol would probably suffer biofuel supply constraints (after allowing for likely sustainable Australian feedstock capacities and roughly equivalent extra volumes from imports).
} 
likely to be required to reduce the costs of some options (where high cost levels will serve to delay or slow their adoption). Any future rises in oil prices will tend to act as a significant incentive, accelerating the take-up of some options. It is possible, however, that a combination of rising fossil fuel prices together with government policies complementing their adoption (by addressing particular social or regulatory constraints affecting various options' acceptance) will be required in order to realise the transport sector abatement potentials identified here by the ALCTF.

\section{Abbreviations}

$\begin{array}{ll}\text { ALCTF } & \text { Australian Low Carbon Transport Forum } \\ \text { BITRE } & \text { Bureau of Infrastructure, Transport and Regional Economics } \\ \mathrm{CO}_{2} \mathrm{e} & \text { Carbon dioxide equivalent } \\ \text { CSIRO } & \text { Commonwealth Scientific and Industrial Research Organisation } \\ \text { DCCEE } & \text { Department of Climate Change and Energy Efficiency } \\ \text { FFC } & \text { full fuel cycle } \\ \text { Gg } & \text { gigagrams, } 10^{9} \text { grams } \\ \text { IEA } & \text { International Energy Agency } \\ \text { Mt } & \text { megatonnes, } 10^{6} \text { tonnes } \\ \text { PBS } & \text { Performance Based Standards } \\ \text { TDM } & \text { transport demand management } \\ \text { UPT } & \text { urban public transport }\end{array}$

\section{References}

${ }^{1}$ Cosgrove, D., Gargett, D., Evans, C., Graham, P., and Ritzinger, A., Greenhouse gas abatement potential of the Australian transport sector: Technical Report, CSIRO, 2012. URL: http://www.csiro.au/ALCTF

${ }^{2}$ CSIRO, Greenhouse gas abatement potential of the Australian transport sector: Summary Report, CSIRO, 2012. URL: http://www.csiro.au/ALCTF

${ }^{3}$ BITRE, Long-term Projections of Australian Transport Emissions: Base Case 2010, Report for the Department of Climate Change and Energy Efficiency, Canberra: BITRE, 2010. URL: http://www.climatechange.gov.au/sites/climatechange/files/files/climatechange/bitre-transport-modelling-pdf.pdf]

${ }^{4}$ Treasury, Australia to 2050: future challenges [Intergenerational report], Department of the Treasury, Canberra, ACT, 2010.

${ }^{5}$ Treasury, Pre-election economic and fiscal outlook 2010, Department of the Treasury, Canberra, ACT, 2010.

${ }^{6}$ IEA, World Energy Outlook 2009, International Energy Agency/OECD, Paris, France, 2009.

${ }^{7}$ Cosgrove, D., "Long-term patterns of Australian public transport use", Australasian Transport Research Forum 2011, Adelaide, Australia: University of South Australia. URL: http://www.atrf.info/papers/2011/2011_Cosgrove.pdf

${ }^{8}$ Commonwealth of Australia, Strong growth, low pollution: modelling a carbon price. Treasury, Australian Government, Canberra, 2011. URL: http://archive.treasury.gov.au/carbonpricemodelling/content/default.asp

${ }^{9}$ DCCEE, Australia's fifth national communication on climate change. Report to the United Nations Framework Convention on Climate Change, DCCEE, Canberra, ACT, 2010. 
${ }^{10}$ Farine, D., O’Connell, D., Raison, J., May, B., O’Connor, M., Herr, A., Taylor, J., Rodriguez, L., Campbell, P., Dunlop, M., Poole, M., Crawford, D., Jovanovic, T., Braid, A., and Kritikos, D., "An assessment of biomass for bioelectricity and biofuel, and greenhouse gas emission reduction in Australia", Global Change Biology: Bioenergy, 4: 148-175, 2011. DOI: http://dx.doi.org/10.1111/j.1757-1707.2011.01115.x 